\title{
A Cross-Sectional Study on Assessment of Oxidative Stress in Coronary Heart Disease Patients in Bangladesh
}

\author{
Mohammad Kamruzzaman, Talita Zahin Choudhury, Tania Rahman, Laila N. Islam* \\ Department of Biochemistry and Molecular Biology, University of Dhaka, Dhaka, Bangladesh \\ Email: *laila@du.ac.bd
}

How to cite this paper: Kamruzzaman, M., Choudhury, T.Z., Rahman, T. and Islam, L.N. (2019) A Cross-Sectional Study on Assessment of Oxidative Stress in Coronary Heart Disease Patients in Bangladesh. World Journal of Cardiovascular Diseases, 9, 331342 .

https://doi.org/10.4236/wjcd.2019.95029

Received: April 10, 2019

Accepted: May 13, 2019

Published: May 16, 2019

Copyright (c) 2019 by author(s) and Scientific Research Publishing Inc. This work is licensed under the Creative Commons Attribution International License (CC BY 4.0).

http://creativecommons.org/licenses/by/4.0/

\section{(c) (i) Open Access}

\begin{abstract}
Oxidative stress is considered a central factor in endothelial dysfunction and plaque formation in coronary heart disease (CHD) patients. In this crosssectional study, the stress-induced protein and lipid oxidation and production of signaling molecule, nitric oxide has been investigated in CHD patients in Bangladesh. A total of 140 participants were enrolled of which 70 were $\mathrm{CHD}$ patients, and the remaining 70 were control subjects having no cardiovascular disease. The diagnosis of CHD was made by expert physicians through characteristic electrocardiogram and troponin changes. The protein carbonyls and thiobarbituric acid reactive substances (TBARS) levels in plasma of both groups were measured by spectrophotometric methods. The plasma nitric oxide levels were measured by reaction with Griess reagent. Statistical non-parametric tests and t-tests were used to analyze the results between the CHD patients and controls. In the patients, the mean protein carbonyls and TBARS, two important markers of oxidative stress, were $2.87 \pm$ $0.97 \mathrm{nmol} / \mathrm{mg}$ and $6.92 \pm 3.56 \mathrm{nmol} / \mathrm{mL}$, respectively, which were significantly higher than in the control subjects, $1.71 \pm 0.82 \mathrm{nmol} / \mathrm{mg}$ and $3.15 \pm$ $1.42 \mathrm{nmol} / \mathrm{mL}$, respectively. Assessment of the cardiovascular signaling molecule nitric oxide showed significantly lower value in the CHD patients (6.29 $\pm 4.78 \mu \mathrm{M})$ compared to the controls $(10.75 \pm 6.03 \mu \mathrm{M})$. There was a significant negative correlation between plasma TBARS and total plasma protein, and a weak negative correlation between TBARS and nitric oxide levels in the CHD patients. Evaluation of the smoking habit strongly suggested that smoking was a risk factor for the development of CHD among the Bangladeshi population. These results provide an overview of oxidative stress-mediated damages on proteins, lipids and effects on signaling molecule nitric oxide in CHD patients.
\end{abstract}




\section{Keywords}

Coronary Heart Disease, Oxidative Stress, TBARS, Protein Carbonyls, Nitric

Oxide

\section{Introduction}

Coronary heart disease (CHD) is associated with a high mortality rate among patients with cardiovascular diseases, which together constitute a leading cause of death and disabling symptoms worldwide. CHD is the narrowing of the arteries that supply blood and oxygen to the heart due to build-up of atheroma and plaque in the arteries, a process termed as atherosclerosis. A decrease in blood supply to the heart due to atherosclerosis, thrombosis and coronary artery spasm is known to induce myocardial ischemia [1]. However, sudden massive increase in oxygen supply causes a burst of oxygen consumption with consequent generation of reactive oxygen species (ROS). Excess production of ROS causes modification of cellular lipids and proteins of myocardium resulting the development and progression of $\mathrm{CHD}$ [2]. Oxidative stress is considered a central factor in endothelial dysfunction and plaque formation.

Epidemiological studies have indicated the rising prevalence of atherosclerosis globally. The World Health Organization estimated that 17.5 million people died from cardiovascular diseases (CVDs) in 2012, representing 31\% of all global deaths. CVDs were responsible for the largest proportion (39\%) of the global noncommunicable disease deaths under the age of 70 . The prevalence of CHD varies considerably in different populations and the risk factor for CHD also varies from different geographic locations and ethnic groups. In China, the incidence of CHD was increased with high cholesterol level, while in Latin America, smoking, obesity and lack of physical activity were reported to be the primary risk factors [3]. Although research shows that the prevalence of CHD has declined in developed countries in recent years, these conditions have increased in the developing countries [4].

There is a dramatic increase in the incidence of CHD in developing countries, particularly low and middle income countries (LMICs), creating a major challenge for the health sector. In 2001, three-fourths of the global deaths due to CHD occurred in the LMICs [5]. The exact prevalence of CHD in Bangladesh is not available but recent data show that approximately $20 \%$ of adults and $40 \%$ $60 \%$ of elderly people suffer from hypertension, and lifestyle related factors like obesity, smoking habit, high salt intake and physical inactivity may play important roles in the development of CHD [6]. Obesity and diabetes mellitus (DM) constitute major risks for CHD. After China and India, Bangladesh has the highest prevalence ( $10 \%$ of the population) of DM among LMICs and the prevalence is supposed to increase $30 \%$ by 2030 [7].

Oxidative stress (OS) is a physical condition where an imbalance between an- 
tioxidants and concentrations of ROS develops. In general terms, the damage caused by ROS features the chemical reaction known as oxidation and ROS attacks on tissue, which is known as oxidative stress. OS leads to cellular injury, such as damage to DNA, proteins, and lipid membranes when the production of ROS exceeds the ability of the body to neutralize it [8]. The cellular injury caused by ROS has been implicated in the disease states such as diabetes, neurodegenerative diseases, cancer, atherosclerosis, and cardiovascular diseases [9].

Due to the very short half-lives of ROS, protein and lipid oxidation are the causally associated molecules to measure oxidative damage. Protein oxidation including loss of function to the proteins, denaturation of proteins, and amino acid oxidation also used as markers for oxidative damage. With increased concentration of oxygen free radicals, there is increase in the formation of carbonyl groups in proteins [10]. Carbonyls are excellent biomarker for protein oxidation. Lipid peroxides are also the most common oxidative biomarkers used to indicate OS. The chance of some diseases associated with OS, such as atherosclerosis, is increased with the increased concentrations of lipid peroxidation end products [11].

Nitric oxide (NO) is an important cardiovascular signaling molecule that keeps the endothelium in shape by curbing inflammation and OS. It maintains the blood pressure and vascular tone, prevents smooth muscle cell proliferation, and inhibits leukocyte adhesion and platelet aggregation [12]. All these functions are important in the protection against onset and progression of CHD. The loss of NO is one of the earliest indicators or markers of heart disease. It has been reported that reduced bioavailability of NO leads to endothelial dysfunction that may increase CHD progression and loss of cardioprotective actions [12].

Although the pathophysiology of atherosclerosis has not been fully elucidated, excessive ROS production plays an essential role in the development of CHD and endothelial dysfunction is linked with high-risk populations. Therefore, this study was undertaken to assess certain biochemical parameters of oxidative stress and its effect on nitric oxide production in the CHD patients in Bangladesh.

\section{Methods}

\subsection{Subjects}

A total of 140 subjects were enrolled in this study; among them 70 were coronary heart disease (CHD) patients admitted to the Cardiology Unit of the Dhaka Medical College Hospital, and the remaining 70 were non-CHD subjects (control group), randomly selected from the employees of different offices having no diabetes mellitus and infectious diseases. The diagnosis of CHD was made by expert physicians through the examination of characteristic electrocardiogram and troponin changes. Exclusion criteria included those suffering from diabetes mellitus, infections, impaired renal and liver function, and chronic obstructive pulmonary disease. 
Before data collection, both the experimental and control group subjects were informed about the study objectives. The guidelines of the Ethical Review Committee of the Faculty of Biological Sciences, University of Dhaka, were strictly followed during sample collection. Only the full consenting individuals were enrolled as the study participants, and the baseline health information were recorded on preformed questionnaire forms.

\subsection{Study Period and Blood Collection}

This study was conducted from January 2016 to June 2017. About $10 \mathrm{~mL}$ of peripheral blood was collected from the study participants with the help of an expert technician and divided equally in 2 vacutainer tubes-one containing EDTA (for plasma) and the other, without anticoagulant (for serum). The samples were brought to the laboratory in an ice chamber. After centrifugation of the blood, plasma and serum were collected in eppendorf tubes and stored at $-20^{\circ} \mathrm{C}$ until analyzed.

\subsection{Assay of Thiobarbituric Acid Reactive Substances}

The thiobarbituric acid reactive substances (TBARS) are formed as a byproduct of lipid peroxidation and used as an index of oxidative stress. In this study, TBARS level was determined according to the method of Yagi [13]. An aliquot of $2.0 \mathrm{~mL}$ working TBA reagent was added to $1.0 \mathrm{~mL}$ of sample $(100 \mu \mathrm{L}$ plasma + $900 \mu \mathrm{L}$ saline) and $30 \mu \mathrm{L}$ of $50 \mathrm{mM}$ butylated hydroxy toluene (BHT) was added. The mixture was incubated for 15 minutes in a boiling water bath and then kept in ice for 15 minutes. The sample tubes were centrifuged for $10 \mathrm{mi}-$ nutes at $2000 \mathrm{rpm}$. Finally, the supernatant was collected to measure the absorbance at $535 \mathrm{~nm}$. The TBARS value of the plasma samples was determined using a standard graph and expressed as malondialdehyde (MDA) equivalent per mL.

\subsection{Protein Carbonyls Assay}

Protein oxidation was estimated by measuring protein carbonyl content of the plasma samples by the method described by Levine et al. [14]. A sample of $40 \mu \mathrm{L}$ of plasma was mixed with $900 \mu \mathrm{L}$ of $10 \mathrm{mM} \mathrm{DNPH} \mathrm{(2,4-dinitrophenyl} \mathrm{hydra-}$ zine) in $2 \mathrm{~N} \mathrm{HCl}$. The blank was prepared by adding $2 \mathrm{~N} \mathrm{HCl}$ in place of DNPH. Both mixtures were then incubated in a dark place for 1 hour at room temperature, vortexed every 10 - 15 minutes, precipitated with 30\% TCA (final concentration) and then centrifuged for $3 \mathrm{~min}$ at $12,000 \mathrm{rpm}$. The pellet was washed three times with $1 \mathrm{~mL}$ ethanol:ethyl acetate $(1: 1, \mathrm{v} / \mathrm{v})$ to remove excess DNPH and dissolved in $1.5 \mathrm{~mL}$ of $10 \% \mathrm{SDS}$ at $37^{\circ} \mathrm{C}$ for 1 hour. Insoluble substances were removed by centrifugation at 12,000 $\mathrm{rpm}$ for $3 \mathrm{~min}$. The differences in the absorbance between the DNPH treated and $\mathrm{HCl}$ treated samples were determined at $360 \mathrm{~nm}$ by using a Shimadzu UV-VIS spectrophotometer. The protein carbonyl contents of the plasma samples were expressed as carbonyl groups $/ \mathrm{mg}$ protein using the extinction coefficient of DNP as $22.0 \mathrm{mM}^{-1} \mathrm{~cm}^{-1}$. 


\subsection{Assay of Total Plasma Protein}

Plasma sample $(20 \mu \mathrm{L})$ was taken in a tube and diluted with $380 \mu \mathrm{L}$ of normal saline $(0.9 \% \mathrm{NaCl})$. After that $1000 \mu \mathrm{L}$ biuret reagent was added and mixed well. The mixture was incubated for 15 minutes at room temperature. A reagent blank was prepared by adding $400 \mu \mathrm{L}$ normal saline with $1000 \mu \mathrm{L}$ biuret reagent. After incubation, absorbance was taken at $540 \mathrm{~nm}$ against the reagent blank. BSA standard protein $(10 \mathrm{mg} / \mathrm{mL})$ was treated in the same way. Different concentrations of BSA were used for the construction of a standard graph. The concentrations of proteins in the plasma samples were determined from the graph.

\subsection{Plasma Nitric Oxide Levels}

An aliquot of $100 \mu \mathrm{L}$ of working Griess reagent, prepared by mixing equal volume of $\mathrm{N}$-(1-naphthyl) ethylenediamine dihydrochloride and sulfanilamide in $5 \%$ phosphoric acid, was added to $0.3 \mathrm{~mL}$ of sample $(100 \mu \mathrm{L}$ plasma $+200 \mu \mathrm{L}$ saline). Then $2.6 \mathrm{~mL}$ of deionized water was added. The mixture was incubated for 30 minutes at room temperature and the absorbance was measured at $548 \mathrm{~nm}$. Different concentrations of sodium nitrite $\left(\mathrm{NaNO}_{2}\right)$ were used to construct a standard graph from which unknown NO level in the plasma samples were determined.

\subsection{Statistical Analysis of the Data}

Data analyses and figure preparations were carried out using the Statistical Package for Social Sciences (SPSS, version 20.0 for Windows) and Graphpad Prism 5.0 (Graphpad Software, Inc., La Jolla, CA). The Student's t-test, and nonparametric Mann-Whitney test and chi-square test were used (where applicable) for comparison between the CHD patients and control subjects; Spearman's correlation tests were used for correlation analyses between different parameters of the study populations. A $p$ value of $<0.05$ was considered significant.

\section{Results}

\subsection{Types of Coronary Heart Disease among the Patients}

Of the CHD patients enrolled in this study $(\mathrm{N}=70), 69 \%$ were diagnosed with ST-segment elevation myocardial infarction (STEMI), 24\% had non-ST-segment elevation myocardial infarction (NSTEMI) and the remaining $7 \%$ were suffering from unstable angina (UA).

\subsection{Baseline Characteristics of the Study Subjects}

The mean age of the CHD patients was $53.7 \pm 11.2$ years, ranging from 21 to 80 years and their mean BMI $\left(\mathrm{kg} / \mathrm{m}^{2}\right)$ was $23.3 \pm 2.6$. The mean duration of chest pain of the patients before admission to the hospital was $15.5 \pm 19.9$ hours that varied from $1-72$ hours with a median of 5 hours. An important diagnostic marker of CHD, Troponin I values of the patients were recorded and the mean was found to be $6.7 \pm 13.9 \mathrm{ng} / \mathrm{mL}$, ranging from 0.02 to $54.00 \mathrm{ng} / \mathrm{mL}$. The pa- 
tients had a mean pulse rate of $80.7 \pm 12.9$ beats per minute (bpm) varying from 56 to $126 \mathrm{bpm}$. The mean systolic blood pressure (SBP) of the CHD patients was $129.1 \pm 21.5 \mathrm{mmHg}$ and the mean diastolic blood pressure (DBP) was $83.8 \pm$ $14.8 \mathrm{mmHg}$.

On the other hand, the mean age of the control subjects was $46.4 \pm 8.8$ years ranging from 24 to 72 years and the mean BMI $\left(\mathrm{kg} / \mathrm{m}^{2}\right)$ was $24.5 \pm 3.8$. They had a mean pulse rate of $77.0 \pm 7.2 \mathrm{bpm}$ varying from 64 to $92 \mathrm{bpm}$. The mean SBP of the control subjects was $121.2 \pm 7.0 \mathrm{mmHg}$ with a median value of $120 \mathrm{mmHg}$ and the mean DBP was $79.6 \pm 7.1 \mathrm{mmHg}$ with a median value of $80 \mathrm{mmHg}$. It was found that the BMI, pulse rate and DBP of the patients were not significantly different from the controls but the SBP was significantly higher in the CHD patients $(\mathrm{p}<0.05)$. In this study, the participants were not age matched and the controls were a few years younger than the patients.

\subsection{Smoking Status of the Study Subjects}

Among the CHD patients, 53\% were current smokers, $26 \%$ were ex-smokers and $21 \%$ were non-smokers. In the control group, $39 \%$ were current smokers, $3 \%$ were ex-smokers and 58\% were non-smokers. A chi-square test revealed that there was a significant difference $(\mathrm{p}<0.001)$ in smoking habit between the CHD patients and control subjects, which strongly suggested that smoking was a risk factor for the development of CHD.

\subsection{Levels of Total Plasma Proteins}

The mean total protein in plasma of the CHD patients was $8.33 \pm 0.92 \mathrm{~g} / \mathrm{dL}$, ranging from 5.95 to $10.31 \mathrm{~g} / \mathrm{dL}$. On the other hand, the control subjects had the mean total protein level of $8.80 \pm 0.81 \mathrm{~g} / \mathrm{dL}$ that ranged from 5.80 to $10.35 \mathrm{~g} / \mathrm{dL}$. Statistical analysis showed the total plasma protein of the CHD patients was significantly lower $(\mathrm{p}<0.01)$ than the controls.

\subsection{Levels of Thiobarbituric Acid Reactive Substances}

The mean TBARS level in the plasma of the CHD patients was found $6.92 \pm 3.56$ $\mathrm{nmol} / \mathrm{mL}$ that ranged from 2.44 to $25.52 \mathrm{nmol} / \mathrm{mL}$ and the median value was $6.06 \mathrm{nmol} / \mathrm{mL}$. In the control subjects, the mean TBARS level was $3.15 \pm 1.42$ $\mathrm{nmol} / \mathrm{mL}$ that ranged from 0.40 to $8.55 \mathrm{nmol} / \mathrm{mL}$ and the median value was 2.90 $\mathrm{nmol} / \mathrm{mL}$. Statistical analysis revealed that the level of TBARS in plasma of the CHD patients was significantly higher $(\mathrm{p}<0.001)$ than the control subjects (Figure 1).

\subsection{Estimation of Protein Carbonyls}

It was found that the plasma protein carbonyls of the CHD patients varied from 1.63 to $5.45 \mathrm{nmol} / \mathrm{mg}$ with a mean value of $2.87 \pm 0.97 \mathrm{nmol} / \mathrm{mg}$. On the other hand, the control subjects had the mean protein carbonyls value of $1.71 \pm 0.82$ $\mathrm{nmol} / \mathrm{mg}$ that ranged from 0.67 to $5.35 \mathrm{nmol} / \mathrm{mg}$. Statistical analysis revealed 
that the CHD patients had significantly higher $(\mathrm{p}<0.001)$ protein carbonyls in plasma than in the control subjects (Figure 2).

\subsection{Nitric Oxide Levels}

By analyzing the nitric oxide levels in the study subjects, it was found that the mean nitric oxide level of the control subjects was $10.75 \pm 6.03 \mu \mathrm{M}$ that varied from $1.80 \mu \mathrm{M}$ to $34.69 \mu \mathrm{M}$. In the CHD patients, the mean nitric oxide level was $6.29 \pm 4.78 \mu \mathrm{M}$ that varied from $0.57 \mu \mathrm{M}$ to $23.01 \mu \mathrm{M}$. The nitric oxide level of the CHD patients was found to be significantly lower $(\mathrm{p}<0.001)$ than the control subjects (Figure 3).

\subsection{Correlation of Total Protein, TBARS and Nitric Oxide in CHD Patients}

Spearman's correlation analysis showed a significant negative correlation $(\mathrm{p}<$ $0.01, r=-0.357$ ) between the total plasma protein and TBARS levels in CHD patients (Figure 4). Also, there was a weak negative correlation between the TBARS and nitric oxide levels in the patients $(\mathrm{p}=0.262, \mathrm{r}=-0.136)$.

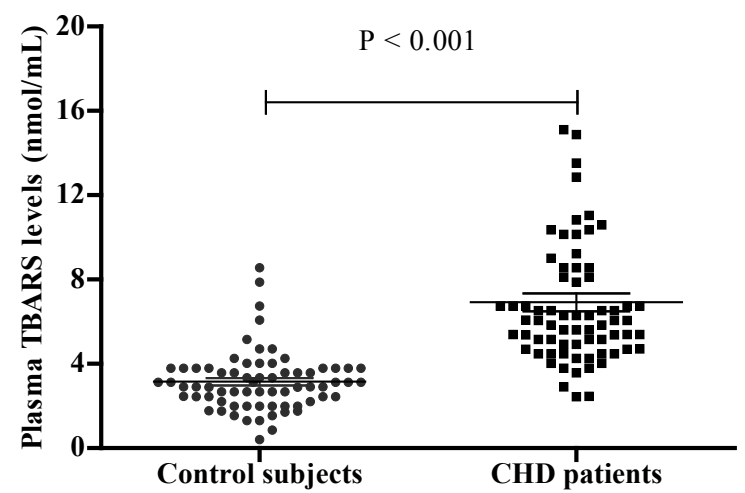

Figure 1. Comparison of plasma TBARS levels between the CHD patients and control subjects. The CHD patients had significantly higher TBARS level than the control subjects $(\mathrm{p}<0.001)$.

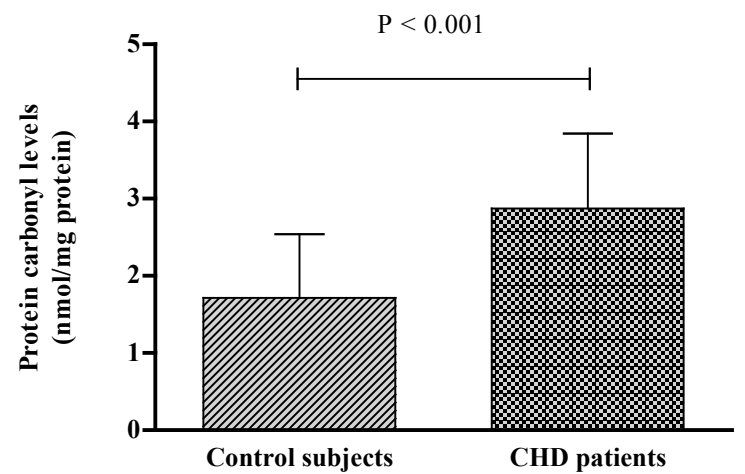

Figure 2. Comparison of plasma protein carbonyl levels between the CHD patients and control subjects. The CHD patients had significantly higher protein carbonyl levels than the control subjects $(\mathrm{p}<0.001)$. 


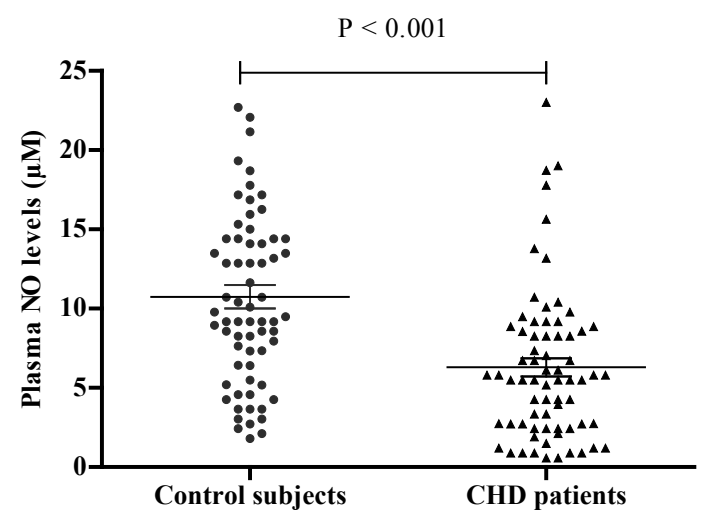

Figure 3. Comparison of plasma nitric oxide levels between the CHD patients and control subjects. The nitric oxide levels of the CHD patients were significantly lower $(\mathrm{p}<0.001)$ than the control subjects.

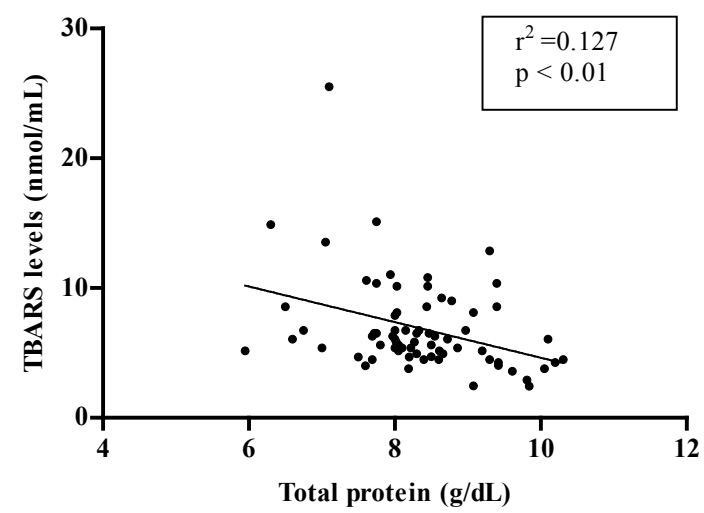

Figure 4. A significant negative correlation between plasma TBARS levels and total protein was found in the CHD patients $(\mathrm{p}<0.01)$.

\section{Discussion}

The present study evaluated the extent of oxidative stress in the CHD patients in Bangladesh. Since diabetes mellitus and several chronic diseases are associated with oxidative stress [15], patients with diabetes mellitus and any other chronic inflammatory condition has been excluded from this study to avoid false positive results. It was found that about $19 \%$ of the CHD patients studied were overweight compared to $28 \%$ of the control subjects, and their mean BMI was not significantly different from the control subjects. One study reported overweight (BMI $\geq 25.0$ ) to be a risk factor for CVD [16]; however, we have not found obesity as a risk factor for CHD.

Among the 70 patients enrolled in this study, 69\% presented with STEMI, $24 \%$ had NSTEMI and $7 \%$ had unstable angina. In the USA, STEMI is responsible for $70 \%$ of all MI cases while $30 \%$ of the cases present with NSTEMI [17], which are similar to the findings of this study. This study found a significant difference in smoking habit between the CHD patients and control subjects. Among the patients, $53 \%$ were current smokers and $26 \%$ were ex-smokers; while in the control subjects, $39 \%$ were current smokers and only $3 \%$ were ex-smokers. 
The chi-square test found a positive, significant relationship between smoking habit and development of CHD. A meta-analysis of individual participant data from prospective cohort studies found smoking as a strong independent risk factor of cardiovascular events [18]. In this study, there was no data on alcohol consumption by the study participants; therefore, this risk factor could not be evaluated.

In the present study, the baseline characteristics of the CHD patients showed no significant difference in pulse rate and DBP compared to the control subjects but the SBP was significantly higher. It is to be noted that the patients were under antihypertensive drugs before collecting the blood samples as they were hospitalized with chest pain. Thus, the blood pressure at the time of blood collection may not reflect the blood pressure at the time or before admission. In this study, the participants were not age matched and the mean age of the control subjects was 46.4 years compared to 53.7 years of the patients. However, owing to the difficulties of obtaining blood samples from elderly subjects with exclusion criteria to be enrolled as controls, the study continued with the current participants.

The mean plasma protein in the CHD patients was found significantly lower than in the control subjects. A similar study carried out in Turkey showed no significant difference in the total plasma protein between the CHD patients and controls [19]. This is suggestive of the fact that the significant variation observed in the current study may have been due to age differences between the patients and the control subjects.

The lipid peroxidation product, MDA was found significantly higher $(\mathrm{p}<$ 0.001) in the CHD patients which was indicative of elevated oxidative stress in these patients. This observation was consistent with the previous researches on the CHD patients [1] [20]. Increased lipid peroxidation is thought to be a consequence of oxidative stress which occurs when the dynamic balance between pro-oxidant and antioxidant mechanisms are impaired. The present study found a significant negative $(\mathrm{p}<0.01)$ correlation between the total plasma protein and TBARS levels in CHD patients, which might be the effect of ongoing oxidative stress in the patients. Lipid peroxidation may alter intrinsic membrane properties due to physicochemical changes of oxidized lipids or cause polymerization of membrane components [21].

Protein carbonyl production is an indication of oxidative stress that depends upon the nature of the ROS. For example, $\mathrm{HOCl}$, a major endogenous oxidizing species derived from myeloperoxidase, induces formation of carbonyl groups in proteins but causes no modification of DNA or lipids. Chlorotyrosyl moieties and aminoacyl adducts on lysine residues are specific markers of oxidation by $\mathrm{HOCl}$ which have been found in human atherosclerotic lesions [22]. Products of protein side chain oxidative modification are relatively stable, and serve as suitable markers for oxidative stress. In the present study, the CHD patients had significantly higher $(\mathrm{p}<0.001)$ protein carbonyls than the controls. Protein carbonyl groups, a biomarker considering their advantages over lipid peroxidation 
products because of their early formation in stress condition was observed by Tejaswi et al. [23].

Nitric oxide has been the subject of intense research since this endothelium derived relaxing factor was first described in 1980. It has a wide range of biological properties that maintain vascular homeostasis, including regulation of local cell growth, modulation of vascular dilator tone, and protection of the vessel from injurious consequences of platelets and other circulating cells. Several risk factors that are associated with atherosclerosis cause diminished release of nitric oxide in the arterial wall either because of impaired synthesis or excessive oxidative degradation [24]. In the present study, the plasma nitric oxide level of the CHD patients was found significantly lower $(\mathrm{p}<0.001)$ than the control subjects. These data were consistent with the results described by another study in the coronary artery disease patients [25]. Lower nitric oxide level in the CHD patients indicated vascular inflammation that could lead to oxidation of lipoprotein and foam cell formation in the artery.

\section{Summary and Conclusion}

Antioxidants constitute the foremost defence system that limits the toxicity associated with free radicals. This study found significantly higher protein carbonyls and TBARS levels in the CHD patients, suggesting elevated oxidative stress; while nitric oxide, an important signaling molecule for endothelial protection, was significantly lower in these patients.

\section{Limitations}

This study has certain limitations. Firstly, the sample size was small to draw a complete picture for a population. Secondly, and more importantly, the mean age of the CHD patients was higher than the control subjects. Due to stringent inclusion criteria, it was difficult to obtain samples from age-matched control subjects. Finally, it could not be checked whether the control subjects enrolled suffered from any underlying illness which may have had an effect on the results.

\section{Acknowledgements}

The authors gratefully thank Professor Dr. Abdul Wadud Chowdhury from the Cardiology Unit of the Dhaka Medical College Hospital for his permission to collect patient samples. We would also like to thank all participants for their consent and participation in the study.

\section{Conflicts of Interest}

The authors declare no conflicts of interest regarding the publication of this paper.

\section{References}

[1] Bagatini, M.D., Martins, C.C., Battisti, V., Gasparetto, D., Da Rosa, C.S., Spanevello, 
R.M., Ahmed, M., Schmatz, R., Schetinger, M.R.C. and Morsch, V.M. (2011) Oxidative Stress versus Antioxidant Defenses in Patients with Acute Myocardial Infarction. Heart and Vessels, 26, 55-63. https://doi.org/10.1007/s00380-010-0029-9

[2] Cross, C.E., Halliwell, B., Borish, E.T., Pryor, W.A., Ames, B.N., Saul, R.L., McCord, J.M. and Harman, D. (1987) Oxygen Radicals and Human Disease. Annals of Internal Medicine, 107, 526-545. https://doi.org/10.7326/0003-4819-107-4-526

[3] Rodríguez, T., Malvezzi, M., Chatenoud, L., Bosetti, C., Levi, F., Negri, E. and La Vecchia, C. (2006) Trends in Mortality from Coronary Heart and Cerebrovascular Diseases in the Americas: 1970-2000. Heart, 92, 453-460. https://doi.org/10.1136/hrt.2004.059295

[4] Sanchis-Gomar, F., Perez-Quilis, C., Leischik, R. and Lucia, A. (2016) Epidemiology of Coronary Heart Disease and Acute Coronary Syndrome. Annals of Translational Medicine, 4, 256-267. https://doi.org/10.21037/atm.2016.06.33

[5] Gaziano, T.A., Bitton, A., Anand, S., Abrahams-Gessel, S. and Murphy, A. (2010) Growing Epidemic of Coronary Heart Disease in Low-and Middle-Income Countries. Current Problems in Cardiology, 35, 72-115. https://doi.org/10.1016/j.cpcardiol.2009.10.002

[6] Islam, A.M. and Majumder, A.A.S. (2013) Coronary Artery Disease in Bangladesh: A Review. Indian Heart Journal, 65, 424-435. https://doi.org/10.1016/j.ihj.2013.06.004

[7] Whiting, D.R., Guariguata, L., Weil, C. and Shaw, J. (2011) IDF Diabetes Atlas: Global Estimates of the Prevalence of Diabetes for 2011 and 2030. Diabetes Research and Clinical Practice, 94, 311-321. https://doi.org/10.1016/j.diabres.2011.10.029

[8] Townsend, D.M., Tew, K.D. and Tapiero, H. (2003) The Importance of Glutathione in Human Disease. Biomedicine \& Pharmacotherapy, 57, 145-155. https://doi.org/10.1016/S0753-3322(03)00043-X

[9] Diaz-Velez, C.R., García-Castiñeiras, S., Mendoza-Ramos, E. and Hernández-López, E. (1996) Increased Malondialdehyde in Peripheral Blood of Patients with Congestive Heart Failure. American Heart Journal, 131, 146-152. https://doi.org/10.1016/S0002-8703(96)90063-0

[10] Griffiths, H.R., Møller, L., Bartosz, G., Bast, A., Bertoni-Freddari, C., Collins, A., Cooke, M., Coolen, S., Haenen, G., Hoberg, A.M., Loft, S., et al. (2002) Biomarkers. Molecular Aspects of Medicine, 23, 101-208. https://doi.org/10.1016/S0098-2997(02)00017-1

[11] Masuda, Y. and Yamamori, Y. (1991) Histological Detection of Lipid Peroxidation Following Infusion of Tert-Butyl Hydroperoxide and ADP-Iron Complex in Perfused Rat Livers. The Japanese Journal of Pharmacology, 56, 133-142.

[12] Naseem, K.M. (2005) The Role of Nitric Oxide in Cardiovascular Diseases. Molecular Aspects of Medicine, 26, 33-65. https://doi.org/10.1016/j.mam.2004.09.003

[13] Yagi, K. (1998) Simple Assay for the Level of Total Lipid Peroxides in Serum or Plasma. In: Armstrong, D., Ed., Free Radical and Antioxidant Protocols. Methods in Molecular Biology ${ }^{T M}$, Vol. 108, Humana Press, New York. https://doi.org/10.1385/0-89603-472-0:101

[14] Levine, R.L., Garland, D., Oliver, C.N., Amici, A., Climent, I., Lenz, A.G., Ahn, B.W., Shaltiel, S. and Stadtman, E.R. (1990) Determination of Carbonyl Content in Oxidatively Modified Proteins. Methods in Enzymology, 186, 464-478. https://doi.org/10.1016/0076-6879(90)86141-H

[15] Matough, F.A., Budin, S.B., Hamid, Z.A., Alwahaibi, N. and Mohamed, J. (2012) 
The Role of Oxidative Stress and Antioxidants in Diabetic Complications. Sultan Qaboos University Medical Journal, 12, 5-18.

[16] Myint, P.K., Kwok, C.S., Luben, R.N., Wareham, N.J. and Khaw, K.T. (2014) Body Fat Percentage, Body Mass Index and Waist-to-Hip Ratio as Predictors of Mortality and Cardiovascular Disease. Heart, 100, 1613-1619. https://doi.org/10.1136/heartjnl-2014-305816

[17] McManus, D.D., Gore, J., Yarzebski, J., Spencer, F., Lessard, D. and Goldberg, R.J. (2011) Recent Trends in the Incidence, Treatment, and Outcomes of Patients with STEMI and NSTEMI. The American Journal of Medicine, 124, 40-47. https://doi.org/10.1016/j.amjmed.2010.07.023

[18] Mons, U., Müezzinler, A., Gellert, C., Schöttker, B., Abnet, C.C., Bobak, M., de Groot, L., Freedman, N.D., Jansen, E., Kee, F. and Kromhout, D. (2015) Impact of Smoking and Smoking Cessation on Cardiovascular Events and Mortality among older Adults: Meta-Analysis of Individual Participant Data from Prospective Cohort Studies of the CHANCES Consortium. BMJ, 350, h1551. https://doi.org/10.1136/bmj.h1551

[19] Özkan, Y., Özkan, E. and Şimşek, B. (2002) Plasma Total Homocysteine and Cysteine Levels as Cardiovascular Risk Factors in Coronary Heart Disease. International Journal of Cardiology, 82, 269-277. https://doi.org/10.1016/S0167-5273(02)00010-4

[20] Kumar, E.P., Mukherjee, R., Senthil, R., Parasuraman, S. and Suresh, B. (2012) Evaluation of Oxidative Stress and Antioxidant Status in Patients with Cardiovascular Disease in Rural Populations of the Nilgiris, South India. ISRN Pharmacology, 2012, Article ID: 941068. https://doi.org/10.5402/2012/941068

[21] Esterbauer, H., Schaur, R.J. and Zollner, H. (1991) Chemistry and Biochemistry of 4-Hydroxynonenal, Malonaldehyde and Related Aldehydes. Free Radical Biology and Medicine, 11, 81-128. https://doi.org/10.1016/0891-5849(91)90192-6

[22] Beal, M.F. (2002) Oxidatively Modified Proteins in Aging and Disease. Free Radical Biology and Medicine, 32, 797-803. https://doi.org/10.1016/S0891-5849(02)00780-3

[23] Tejaswi, G., Suchitra, M.M., Rajasekhar, D., Kiranmayi, V.S. and Rao, P.S. (2017) Myeloperoxidase, Protein Carbonyls and Oxidative Stress in Coronary Artery Disease. Journal of Indian College of Cardiology, 7, 149-152. https://doi.org/10.1016/j.jicc.2017.10.004

[24] Cannon, R.O. (1998) Role of Nitric Oxide in Cardiovascular Disease: Focus on the Endothelium. Clinical Chemistry, 44, 1809-1819.

[25] Gürlek, A., Esenboğa, K., Özcan, Ö.U., Çiçek, Ö.F., Ayral, P.A., Kavas, G.Ö. and Erol, Ç. (2016) Serum Nitric Oxide Levels in Patients with Coronary Artery Ectasia. Anatolian Journal of Cardiology, 16, 947.

https://doi.org/10.14744/AnatolJCardiol.2016.6556 